\title{
Factors Affecting Dimorphism in Mycotypha (Mucorales): a Correlation with the Fermentation/Respiration Equilibrium
}

\author{
By BARBARA E. SCHULZ, GUNDA KRAEPELIN \\ AND W. HINKELMANN \\ Institute of Botany, Technical University, 33 Braunschweig, \\ German Federal Republic
}

(Received 2 May 1973; revised 2 January 1974)

\section{SUMMARY}

The yeast/mould (Y/M) dimorphism of three strains of the genus Mycotypha (Zygomycetes, Mucorales) was investigated. The Y-form is most readily induced in $M$. africana (CBSI22.64), whereas M. microspora (CBS230.32) has a strong tendency to grow as M-form. The Y-form is promoted by anaerobiosis, increased $P_{\mathrm{CO}_{2}}$, increased temperatures, $\mathrm{pH}$ values between 5.8 and 6.5 , and $10 \%(\mathrm{w} / \mathrm{v})$ glucose in the culture medium, as well as by the addition of certain inhibitors of the respiratory chain or mitochondrial protein synthesis. In contrast, M-form is stimulated by aerobic conditions, by temperatures below approximately $20^{\circ} \mathrm{C}$ and at $\mathrm{pH}$ values below $4 \cdot 5$ and above $7 \cdot 4$. Ultraviolet-induced mutants with a defective respiratory system invariably grow as pure Y-form. Suppression of aerobic metabolism leads to a simultaneous suppression of mycelial growth. This correlation was confirmed by studies of fine structure with the electron microscope.

\section{INTRODUCTION}

The question - what enables a dimorphic fungus to grow either as mycelium (M-form) or as a budding yeast-like form (Y-form)? - has long puzzled biologists (Scherr \& Weaver, 1953; Romano, 1966; Bartnicki-García, 1968). Over a hundred years ago, Pasteur observed that Mucor grew in a yeast-like form at the bottom of a standing liquid culture, while on the surface it developed as mycelium. He presumed that the yeast-like growth was induced by lack of oxygen (Pasteur, I876; cited by Bartnicki-García, 1963).

In recent years many of the factors that cause the various dimorphic fungi to switch their morphologies between $\mathrm{Y}$ - and $\mathrm{M}$-forms have been elucidated. For example, a temperature of $37^{\circ} \mathrm{C}$ causes Blastomyces dermatitidis, Paracoccidioides brasiliensis and Candida albicans to grow as $\mathrm{Y}$-form, whereas at $28^{\circ} \mathrm{C}$ they grow as M-form (Romano, I966; Kanetsuna \& Carbonell, 197I; Ramirez-Martinez, I97I). In Mucor rouxii the tendency to grow yeast-like is enhanced by $\mathrm{CO}_{2}$, increased glucose concentration, anaerobiosis, addition of sodium fluoride or phenylethyl alcohol (Bartnicki-García \& Nickerson, 1962 $a, b$; Haidle \& Storck, I966a; Terenzi \& Storck, 1969). Storck \& Morrill (197I) discovered that respiratory deficiency in Mucor bacilliformis, introduced by spontaneous mutation, resulted in an obligatory Y-form. This verified the earlier hypothesis (e.g. Haidle \& Storck, 1966 $b$ ) that fermentation is correlated with $\mathrm{Y}$-form and respiration with $\mathrm{M}$-form.

We are using Mycotypha, a member of the Mucorales (Zygomycetes), to study Y/Mdimorphism. Mycotypha readily switches its morphology in response to even more factors than those previously mentioned. The three strains we have used differ from each other in their innate tendencies to grow as $\mathrm{Y}$ - or M-form; $M$. microspora CBS230.32 tends to 
M-growth, $M$. africana CBSI22.64 to Y-growth and M. microspora CBSI86.64 usually reacts intermediately.

\section{METHODS}

Strains. Mycotypha africana Novak \& Backus (CBSI22.64) and M. microspora Fenner (CBS230.32) were obtained from the Centraalbureau voor Schimmelcultures, Baarn, The Netherlands. M. microspora (CBSI86.68) was isolated in our laboratory from rotting wood.

Media. Cultures were usually grown in GYP (glucose-yeast extract-peptone) medium consisting of ( $\mathrm{g} / 1$ deionized water): glucose, I00; Bacto yeast extract (Oxoid), 2.5 ; peptone, tryptic digest from meat (Merck), $5 \cdot 0$; L-asparagine, I $\cdot 0 ; \mathrm{KH}_{2} \mathrm{PO}_{4}, \mathrm{I} \cdot 5 ; \mathrm{MgSO}_{4} \cdot 7 \mathrm{H}_{2} \mathrm{O}$, 0.5 ; and, depending on whether or not a solid medium was desired, crude agar, 25. FYP (fructose-yeast extract-peptone) medium contained $100 \mathrm{~g}$ fructose instead of glucose.

Standard conditions. Unless otherwise stated, 'standard conditions' were used, meaning cultured in GYP liquid or on solid medium inoculated with a sporangiole suspension. For shake cultures $(20 \mathrm{ml}$ in a $100 \mathrm{ml}$ Erlenmeyer flask) a rotatory shaker with radius of gyration $2.4 \mathrm{~cm}$ at approximately $150 \mathrm{rev}$. $/ \mathrm{min}$ was used. Incubation was at $28{ }^{\circ} \mathrm{C}$.

Inhibitors. Amytal, antimycin A, chloramphenicol, cycloheximide, oligomycin, rotenone and thenoyltrifluoracetone were obtained from Serva Feinbiochemica, Heidelberg, West Germany; 2,4-dinitrophenol and potassium cyanide from Merck; and $\beta$-phenylethyl alcohol from Schuchard, München, West Germany. The inhibitors were dissolved in the appropriate solute, sterilized by membrane filtration and added to the sterile liquid medium.

Inocula. Sporangioles for the inoculum were harvested from a I- to 4-week-old GYP agar culture, which had been grown under 'standard conditions', by pouring sterile deionized water on the culture and scratching with a loop. The stock suspension was counted in a Thoma haemocytometer and diluted before inoculation to the desired concentration with sterile deionized water.

Variation of the atmosphere. Anaerobic conditions were created by evacuating 31 Mason jars, which contained the inoculated agar plates, to approximately $25 \mathrm{~mm} \mathrm{Hg}$. The jars were then refilled to atmospheric pressure with purified $\mathrm{N}_{2}(99.96 \%)$ or purified argon. When necessary pyrogallol and $\mathrm{KOH}$ were present in the jars to absorb residual $\mathrm{O}_{2}$ and the $\mathrm{CO}_{2}$ produced. When a $5 \%(\mathrm{v} / \mathrm{v}) \mathrm{CO}_{2}$-atmosphere was desired, the evacuated Mason jar was refilled with a $5 \%(\mathrm{v} / \mathrm{v}) \mathrm{CO}_{2}$-air mixture. Pyrogallol and $\mathrm{KOH}$ were omitted, and a $5 \%(\mathrm{v} / \mathrm{v}) \mathrm{CO}_{2}$-buffer was used to maintain constant $\mathrm{PCO}_{2}$. The buffer consisted of: $\mathrm{KHCO}_{3}, 20.0 \mathrm{I} \mathrm{g} ; \mathrm{K}_{2} \mathrm{CO}_{3}, \mathrm{I} \cdot 38 \mathrm{~g}$; thiourea, 0.I0 $\mathrm{g}$; deionized water, I00 ml. For one hour before use, the buffer was saturated with a mixture of $5 \%(\mathrm{v} / \mathrm{v}) \mathrm{CO}_{2}$ in air.

Morphological evaluation. Evaluation of morphology had to be made subjectively, since no adequate method was found for separating short hyphae and Y-forms mechanically. Random fields were examined at magnifications of 120 or $300 \times$ or both, and the proportion of the fields covered by $\mathrm{Y}$ - and $\mathrm{M}$-forms was estimated. ' $\mathrm{Y} 50 \%$ ' means that the observed area was covered half by $\mathrm{Y}$ - and half by M-forms. From homogeneous cultures 5 to 30 fields from one or two samples were usually adequate for a reliable evaluation. For heterogeneous cultures up to 300 fields from two to four samples were needed. All evaluations were made by the same observer. Therefore a blind sampling of the already evaluated cultures was occasionally made to assure the validity of the morphological estimates.

Determination of wet weight. Wet weight was determined by filtering the entire liquid culture through a $8 \mu \mathrm{m}$ pore size Selectron filter (Schleicher \& Schüll, Dassel, West 
Germany) in a Sartorius filter apparatus. The whole cell mass (between 0.3 and $\mathrm{I} \cdot 2 \mathrm{~g}$ ) was then washed twice with deionized water, immediately scraped from the filter and weighed. Experiments were repeated at least once.

Mutants. Y-form mutants were induced by irradiating a sporangiole suspension in deionized water with a germicidal lamp ('Sterisol', Original Hanau Quarzlampen GmbH, Hanau, West Germany) at $254 \mathrm{~nm}$. After plating on GYP agar and a 2 to 3 day incubation, Y-form colonies could be screened visually.

Test for respiratory activity. 2,3,5-Triphenyltetrazolium chloride (TTC) was used to test for the presence of a functional respiratory system. The overlay technique for respiratory defective yeasts (Ogur, John \& Nagai, 1957) was used.

Electron microscopy. Material for electron microscopic sections was taken from $28^{\circ} \mathrm{C}$ GYP or FYP liquid shake cultures. Fixation was in $3 \%$ glutaraldehyde (phosphate buffer $\mathrm{pH} 7 \cdot 0$ ) for $\mathrm{I} 6 \mathrm{~h}$ and post-fixation in unbuffered $2 \%$ potassium permanganate for 20 to $30 \mathrm{~min}$. The samples were embedded in Araldite or Epikote. After staining with lead citrate, sections were examined under a Philips EM 300 electron microscope.

\section{RESULTS}

\section{Variation of the atmosphere}

The main atmospheric change readily affecting the morphology of Mucor rouxii was the addition of $\mathrm{CO}_{2}$ (Bartnicki-García \& Nickerson, $\mathrm{I} 962 \mathrm{~b}$ ). In all three Mycotypha strains, not only $\mathrm{CO}_{2}(4$ to $5 \%, \mathrm{v} / \mathrm{v})$ but also anaerobiosis - argon or $\mathrm{N}_{2}$ - readily promoted $\mathrm{Y}$ growth even on solid GYP medium. The inocula were dilute enough to allow the development of single colonies and to hinder the crowding effect which promotes $\mathrm{Y}$-form. This effect was also observed by Bartnicki-García \& Nickerson (1962a). They found that heavily inoculated liquid cultures of Mucor rouxii $\left(3.6 \times 10^{5}\right.$ spores $\left./ \mathrm{ml}\right)$ developed in the yeast-like form even under nitrogen without additional $\mathrm{CO}_{2}$. As shown in Table I, with Mycotypha microspora CBS230.32 pure Y-growth can only be obtained by adding $\mathrm{CO}_{2}$ under vacuum conditions. In contrast, the other two strains are much more sensitive towards a restriction of oxygen supply.

Perhaps the promotion, under standard conditions without additional $\mathrm{CO}_{2}$, of $\mathrm{Y}$-growth by $\mathrm{IO}^{-8} \mathrm{M}$-biotin (the coenzyme of PEP-carboxylase) is also relevant to Y-form enhancement by increased $\mathrm{PCO}_{2}$. This suggests that the $\mathrm{CO}_{2}$ effect may result from a stimulated $\mathrm{CO}_{2}$ fixation.

Table I. Influence of various atmospheres on the percentage of Y-growth of Mycotypha

\begin{tabular}{|c|c|c|c|}
\hline Atmosphere & $\begin{array}{l}\text { M. africana } \\
\text { CDSI } 22.64\end{array}$ & $\begin{array}{l}\text { M. microspora } \\
\text { CBSI } 86.68\end{array}$ & $\begin{array}{l}\text { M. microspora } \\
\text { CBS230.32 }\end{array}$ \\
\hline $\begin{array}{l}\text { Air (control) } \\
\text { Vacuum }(25 \mathrm{~mm} \mathrm{Hg})(\mathrm{p}, \mathrm{K})\end{array}$ & $\underline{5}$ & $\begin{array}{r}3 \\
100\end{array}$ & $\stackrel{0}{-}$ \\
\hline Argon (approx. $97 \%)(\mathbf{p}, \mathbf{K})$ & 100 & 100 & 60 \\
\hline Nitrogen (approx. $97 \%)(p, K)$ & 100 & 100 & 33 \\
\hline $\mathrm{Air}+5 \% \mathrm{CO}_{2}$ & 100 & 100 & 5 \\
\hline 'Vacuum' $+\mathrm{CO}_{2}{ }^{*}(\mathrm{p})$ & 100 & 100 & 100 \\
\hline Nitrogen $+5 \% \mathrm{CO}_{2}(p)$ & 100 & 100 & 67 \\
\hline
\end{tabular}




\section{Variation of temperature}

The morphology of the three Mycotypha strains was evaluated subjectively after growth in GYP liquid shake culture and on GYP agar medium over a temperature range from 3 to $45^{\circ} \mathrm{C}$. The reaction of Mycotypha to elevated temperature was similar to that of other fungi with a temperature-dependent dimorphism. The proportion of Y-form increased discontinuously with increasing temperature (Fig. I). Moreover, the three strains showed remarkable differences in their sensitivity. While the upper limit of pure M-growth was about $37^{\circ} \mathrm{C}$ in $M$. microscopra $\mathrm{CBS} 230.32$ and about $15^{\circ} \mathrm{C}$ in $M$. africana, a constant level of about $13 \%$ Y-form was maintained over the whole range between II and $35^{\circ} \mathrm{C}$ in $M$. microspora CBSI 86.68. In this strain, pure M-growth was only observed at $7{ }^{\circ} \mathrm{C}$, and a strong stimulation of $\mathrm{Y}$-growth only above $35^{\circ} \mathrm{C}$.

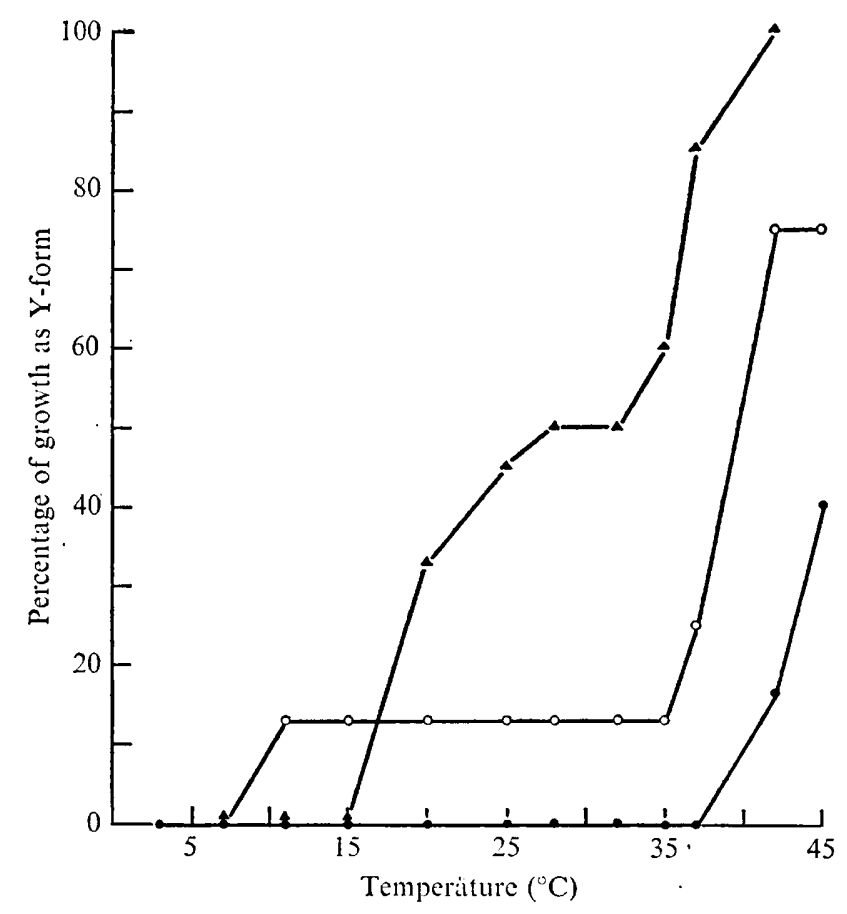

Fig. I. Influence of temperature within the range of 3 to $45^{\circ} \mathrm{C}$ on the morphology of Mycotypha. $M$. microspora CBS230.32 (O), $M$. microspora CBSI $86.68(\bigcirc)$, and $M$. africana $(\Delta)$ were cultured for 8 days (the 3,7 and I I ${ }^{\circ} \mathrm{C}$ cultures for 28 days since growth was slight) on GYP agar.

The stepwise changes in the proportion of $\mathrm{Y}$ - and $\mathrm{M}$-forms at certain temperatures, as well as the different reactions of the three strains, cannot be explained at present, but they clearly show the complex effect of temperature on morphogenetic determination. The temperature for maximal growth yield, measured as wet weight, was $35^{\circ} \mathrm{C}$ for all three Mycotypha strains.

\section{Variation of $p H$}

The influence of the $\mathrm{pH}$ of the culture medium on the morphology of Mycotypha was tested in liquid shake culture (GYP, $28^{\circ} \mathrm{C}$ ) within the $\mathrm{pH}$ range $2 \cdot 2$ to $7 \cdot 5$. With all three 


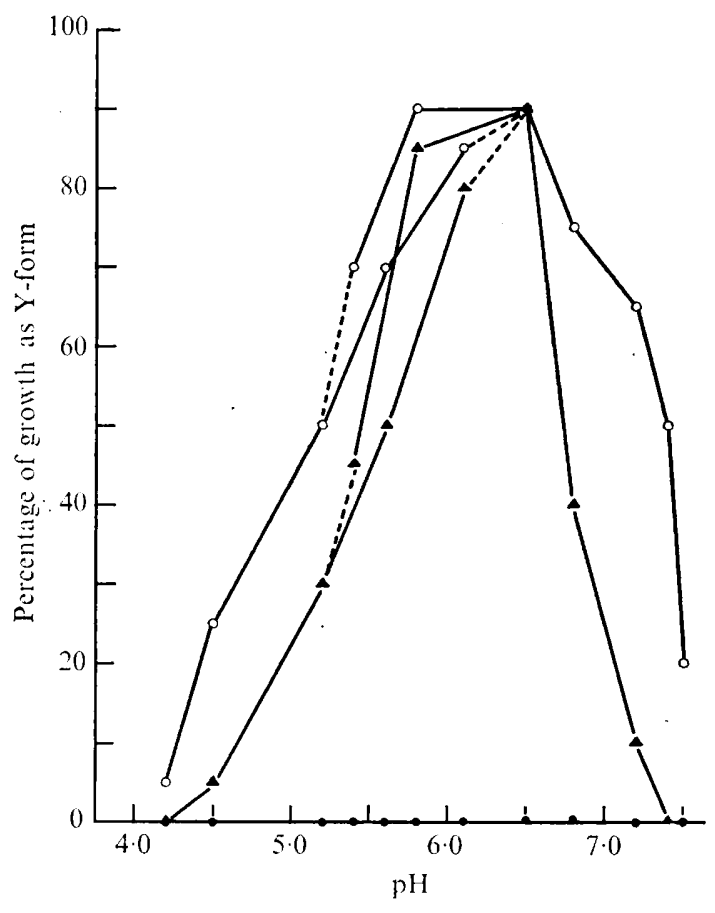

Fig. 2. Influence of $\mathrm{pH}$ of the culture medium on morphology of Mycotypha. $M$. microspora CBS230.32 (O), $M$. microspora CBS I86.68 (O) and $M$. africana $(\Delta)$ were cultured for I day at $28^{\circ} \mathrm{C}$ in GYP liquid medium (I $2 \mathrm{rev} / \mathrm{min}$ ). $\mathrm{HCl}: \mathrm{K}$-phthalate buffer was used over the pH range $2 \cdot 2$ to $6 \cdot 1$ and phosphate buffer over the range $5 \cdot 4$ to $7 \cdot 5$, so the curves for the two buffers overlap in the $\mathrm{pH}$ range 5.4 to $6 \cdot \mathrm{I}$. No growth occurred at $\mathrm{pH} 2 \cdot 2$ and 3.0 .

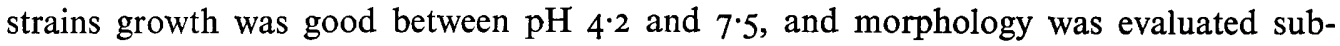
jectively. Since preliminary experiments had revealed rather strong deviations from initial $\mathrm{pH}$ during growth, buffers were used to maintain constant $\mathrm{pH}$ values over the entire experiment (Fig. 2).

The effect of $\mathrm{pH}$ on morphology was very pronounced in $M$. africana and $M$. microspora CBSI86.68. Maximal Y-growth stimulation, reaching or exceeding $90 \%$ Y-form, was found within the $\mathrm{pH}$ range 5.8 to 6.5 . In contrast, $M$. microspora CBS230.32, which was characterized by a strong predominance of $\mathrm{M}$-form, did not change its morphology within the $\mathrm{pH}$ range tested. Growth yield, measured as wet weight over the same $\mathrm{pH}$ range, demonstrated a similar strain dependence: no clear-cut maximum was found for $M$. microspora CBS230.32, while the other two strains reached a pronounced maximum within the same $\mathrm{pH}$ range as the maximum of Y-form (unpublished data).

\section{Variation of glucose concentration}

Glucose concentrations higher than I \% stimulate Y-growth in dimorphic Mucor species (Bartnicki-García, I968; Terenzi \& Storck, 1969). We therefore studied the behaviour of the three Mycotypha strains in liquid shake culture in a GYP medium with $\mathrm{r} \%$ and $10 \%$ glucose (Fig. 3). In the GYP medium with Io \% glucose (standard conditions), the growth of $M$. africana and $M$. microspora CBSI 86.68 after 4 days was approximately $55 \%$ Y-form. When the glucose concentration was reduced from 10 to $\mathrm{I} \%$, a promotion of M-development was observed in both strains. In contrast, M. microspora CBS230.32 grew $100 \%$ 


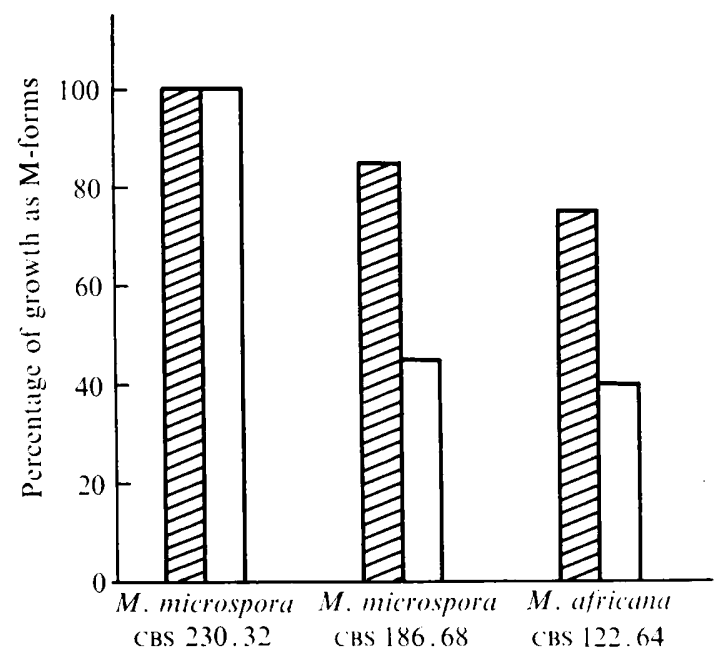

Fig. 3. Influence of $\mathrm{I} \%(\square)$ and $10 \%(\square)$ glucose concentration on morphology of Mycotypha. The GYP liquid shake cultures were evaluated (see Methods) following 4 days growth at $28^{\circ} \mathrm{C}$.

M-form at both glucose concentrations, demonstrating the predominance of M-morphology in this strain. Addition of I or $10 \%$ fructose instead of glucose (FYP medium) did not produce a comparable effect, both concentrations resulting in predominantly $\mathrm{M}$-form with all strains. These results suggest that the suppressing effect of $10 \%$ glucose on mycelial development was caused by its known repressing action on respiratory enzymes, as well as on other inducible systems (Bleeg et al. 1972; Foury \& Goffeau, 1972). On the other hand, the relative insensitivity of $M$. microspora CBS230.32 may result from a different regulation of specific enzymes.

\section{Inhibition of protein synthesis and respiration}

Scherr \& Weaver (1953) and Terenzi \& Storck (1969) have already suggested a correlation of Y-form with fermentation and of M-form with respiration. Terenzi and Storck's conclusion resulted from their use of phenylethyl alcohol with Mucor rouxii. Phenylethyl alcohol is known to inhibit respiration and thus increase fermentation rate, either through an inhibition of mitochondrial protein synthesis (Lewin, 1970) or through damage at the membrane level (Nunn \& Tropp, 1972). Storck \& Morrill (I97I) also provided evidence for the validity of the correlation above; they found spontaneous respiratory-defective mutants of Mucor bacilliformis that grew obligatorily as Y-form and no longer showed cytochrome oxidase activity.

We, too, think that there is a correlation between $\mathrm{Y}$-growth and fermentation and between $\mathrm{M}$-growth and respiration in Mycotypha. In support of this hypothesis, we cite the effects of anaerobiosis/aerobiosis and the repressing effect of glucose on M-growth. Moreover, by irradiating $M$. microspora CBSI 86.68 with u.v., we have obtained various stable mutants, some of which are respiratory defective and invariably Y-form. These mutants were found to be TTC-negative and at least one strain lacked the cytochrome $a a_{3}$ absorption band in its cytochrome spectrum, similar to the Mucor mutant of Storck \& Morrill (197I). We therefore tested the effects of some inhibitors of protein synthesis and respiration on the morphology of the three Mycotypha wild-type strains. 
$\beta$-Phenylethyl alcohol. Twenty hours after inoculation into shaken liquid GYP medium with $0.17 \%(\mathrm{v} / \mathrm{v}) \beta$-phenylethyl alcohol, all three Mycotypha strains grew entirely as $\mathrm{Y}$ form (Table 2). At the same time, the control cultures of $M$. africana and M. microspora CBSI 86.68 - but not $M$. microspora CBS230.32 - had developed as $40 \% \mathrm{M}$-form. Two days later the M. microspora strains also produced some M-form in the treated cultures, perhaps because of evaporation of the phenylethyl alcohol. These M-cells did, however, retain a more yeast-like appearance than their control counterparts.

Chloramphenicol and cycloheximide. Since phenylethyl alcohol caused Mycotypha to grow as pure Y-form, we decided to test the effects of an inhibitor of mitochondrial protein synthesis - chloramphenicol - and of one inhibiting only cytoplasmic protein synthesis cycloheximide (Table 2). The experiments were run under standard conditions in liquid shake culture. Chloramphenicol at $\mathrm{I} \times \mathrm{IO}^{-3} \mathrm{M}$ enhanced $\mathrm{Y}$-form in all three strains. Cycloheximide, on the other hand, had no significant effect on morphology. At $1 \times 10^{-4} \mathrm{M}$ growth was inhibited in all strains. Thus, an inhibition of mitochondrial protein synthesis, necessary for maintaining respiration, resulted in an increased percentage of growth as Y-form. Inhibition of cytoplasmic protein synthesis, responsible for a broader spectrum of substances - including components necessary for respiration and fermentation - stopped growth without any other significant effect.

Inhibition of electron transport and oxidative phosphorylation. If the enhancement of Y-growth caused by chloramphenicol is mediated by an inhibition of respiration, it should be possible to induce Y-form by blocking the electron transport chain or its energy generation. The following inhibitors were therefore tested by addition to GYP liquid shake culture under standard conditions: rotenone, amytal, thenoyltrifluoracetone, antimycin A, potassium cyanide, oligomycin and 2,4-dinitrophenol (Table 2). The probable sites of action and the morphogenetic or toxic effects of these agents are also included in the scheme in Fig. 4.

From the data in Table 2, we suggest that when electron transport is blocked so that electrons can no longer be transferred to oxygen - as in the case of antimycin A or KCNdifferentiation into M-form becomes suppressed in favour of $\mathrm{Y}$-growth, the extent of the morphological shift depending on the concentration used. If, however, the inhibition of electron transport is only partial and a bypass is still possible - as in the case of amytal, rotenone, or thenoyltrifluoracetone - morphology either remains unchanged or M-form is even slightly stimulated (e.g. Mycotypha africana with rotenone). Concerning oxidative phosphorylation, uncoupling with 2,4-dinitrophenol merely produced growth inhibition at a concentration of $\mathrm{IO}^{-3} \mathrm{M}$ without stimulating Y-form at lower concentrations. Inhibition of oxidative phosphorylation by oligomycin, in contrast, had a rather strong $\mathrm{Y}$-inducing effect at concentrations of about $\mathrm{IO}^{-5} \mathrm{M}$.

\section{Electron microscopy}

If the correlation between fermentation/respiration activity and $\mathrm{Y} / \mathrm{M}$-growth is valid, electron microscopy should reveal significant cytological differences. This was so in sections examined from the three cell types, namely Y-form, M-form and the dimorphic cells (D-form) which simultaneously produce $\mathrm{Y}$ - and M-outgrowths (Fig. 5).

Y-form (Fig. 5a) was typified by a cytology often found in other fungi when fermentation prevails: few, often swollen mitochondria, ER-membranes (membranes of the endoplasmic reticulum) concentrated network-like beneath the cell membrane, and numerous lipid inclusions (Bussel, Buckley, Somner \& Kosuge, 1969; McClary \& Bowers, 1967; ClarkWalker, 1972). Also of note was the strikingly thicker and more layered cell wall of Y-form, 
Table 2. Influence of inhibitors of protein synthesis and respiration on the percentage of $Y$-growth of Mycotypha

Inhibitors were added at the final concentrations indicated to liquid GYP cultures under standard conditions and evaluated subjectively after 3 days. Results are expressed as approximate percentages of total growth in Y-form.

Inhibitor (molar concn.)

$\beta$-phenylethyl alcohol

$$
\text { Control }
$$

$1 \cdot 42 \times 10^{-2}$

Chloramphenicol

\section{Control}

$\mathrm{I} \times \mathrm{IO}^{-4}$

$\mathrm{I} \times 1 \mathrm{O}^{-3}$

$5 \times 10^{-3}$

Cycloheximide

Control

$\mathrm{I} \cdot 4 \times \mathrm{IO}^{-8}$

I. $4 \times 10^{-7}$

$7 \times 10^{-6}$

$7 \times 10^{-5}$

$\mathrm{I} \times 10^{-4}$

Rotenone

Control

$\mathrm{I} \times \mathrm{IO}^{-6}$

$\mathrm{I} \times \mathrm{IO}^{-4}$

$1 \times 10^{-3}$

Amytal

Control

$\mathrm{I} \times \mathrm{IO}^{-7}$

$1 \times 10^{-6}$

$\mathrm{I} \times 1 \mathrm{I}^{-3}$

$\mathrm{I} \times 10^{-4}$

Thenoyltrifluoracetone

$$
\begin{aligned}
& \text { Control } \\
& I \times 10^{-6} \\
& I \times 10^{-5} \\
& I \times 10^{-4}
\end{aligned}
$$

Antimycin A

Control

$\mathrm{I} \times \mathrm{IO}^{-7}$

$\mathrm{I} \times 10^{-6}$

$\mathrm{I} \times 10^{-5}$

$\mathrm{I} \times 1 \mathrm{I}^{-4}$

$3 \times 10^{-4}$

Potassium cyanide

Control

$\mathrm{I} \times 10^{-5}$

$1 \times 10^{-4}$

$2 \times 10^{-4}$

$\mathrm{I} \times \mathrm{IO}^{-3}$

$2 \times 10^{-3}$

Oligomycin

Control

$7.6 \times 10^{-6}$

$\mathrm{I} \cdot 2 \times 10^{-5}$

$6.7 \times 10^{-5}$

2,4-Dinitrophenol

Control

$\mathrm{I} \times \mathrm{IO}^{-5}$

$1 \times 10^{-4}$

$\mathrm{I} \times 1 \mathrm{O}^{-3}$

\section{M. africana CBSI 22. 64}

60

100

60

75

100

100

70

70

60

Min. growth

No growth

60
50
33
25

60

40

75

50

50

60

60

56

No growth

60

67

85

100

100

100

60

$\overline{-}$

60

75

60

83

I00

60

75

75

No growth M. microspora
CBSI 86.68

M. microspora CBS230. 32

$\begin{array}{cr}60 & 0 \\ 100 & 100 \\ & \\ 55 & 0 \\ 55 & 0 \\ 75 & 72 \\ \text { No growth } & 67\end{array}$

No growth

67

$\circ$

每

0

0

67

$\begin{array}{ll}50 & 0 \\ 50 & 0 \\ 55 & 0 \\ 50 & 0 \\ 50 & 0\end{array}$

No growth No growth

$\begin{array}{ll}50 & 0 \\ 50 & 0 \\ 33 & 0 \\ 50 & 0\end{array}$

$60 \quad 0$

$\overline{75}$

$50 \quad 0$

33

60

56

56

No growth

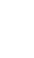

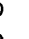

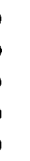




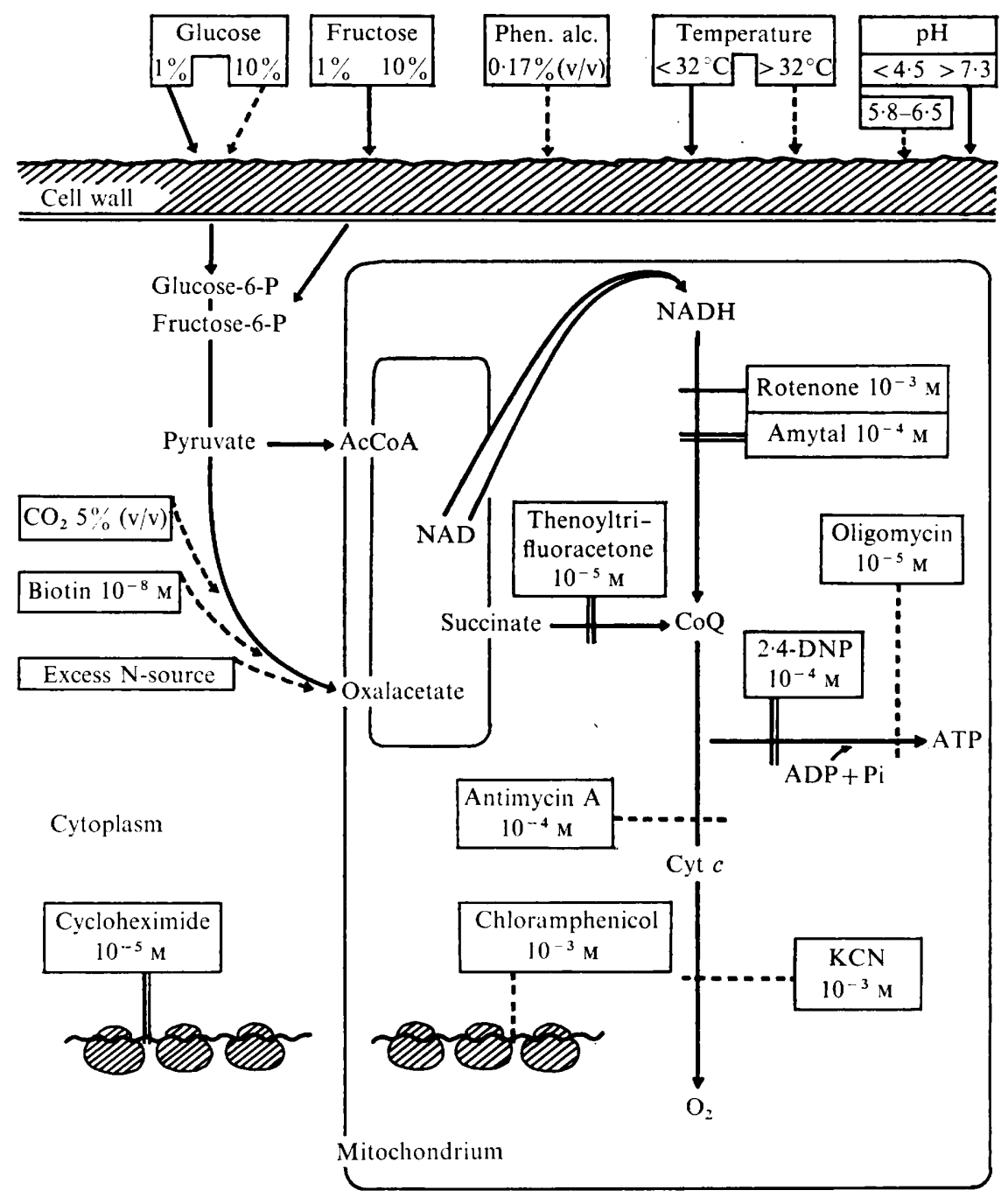

Fig. 4. Summary of the factors tested for their influence on the morphology of Mycotypha. Details of culture are included in the text; see Table 2 for the concentrations tested. Factors and their most effective concentration ranges are framed. Their influences on morphology are indicated as follows:-- - - Y-enhancing; $\longrightarrow$-enhancing; $=$ no significant effect on morphology, or solely growth inhibitory. CoQ, coenzyme Q.

already visible in the light microscope; this was most conspicuous in $M$. microspora CBSI 86.68. As the main characteristics for sections of M-form (Fig. 5b), we found many well developed mitochondria, but only few ER-membranes associated with the cell membrane and no typical lipid inclusions. The D-form cell complexes (Fig. $5 c$ ) confirmed clearly the differences between Y- and M-cytology: the parts of a dimorphic mother cell initiating a mycelial outgrowth showed the characteristic fine structure of M-form, while the budding part showed that of Y-form. Summarizing these observations, it seems to us that the number and localization within the cell of certain fine structures could indeed be evaluated to give a reliable expression of metabolic activities related to Y/M-determination. 

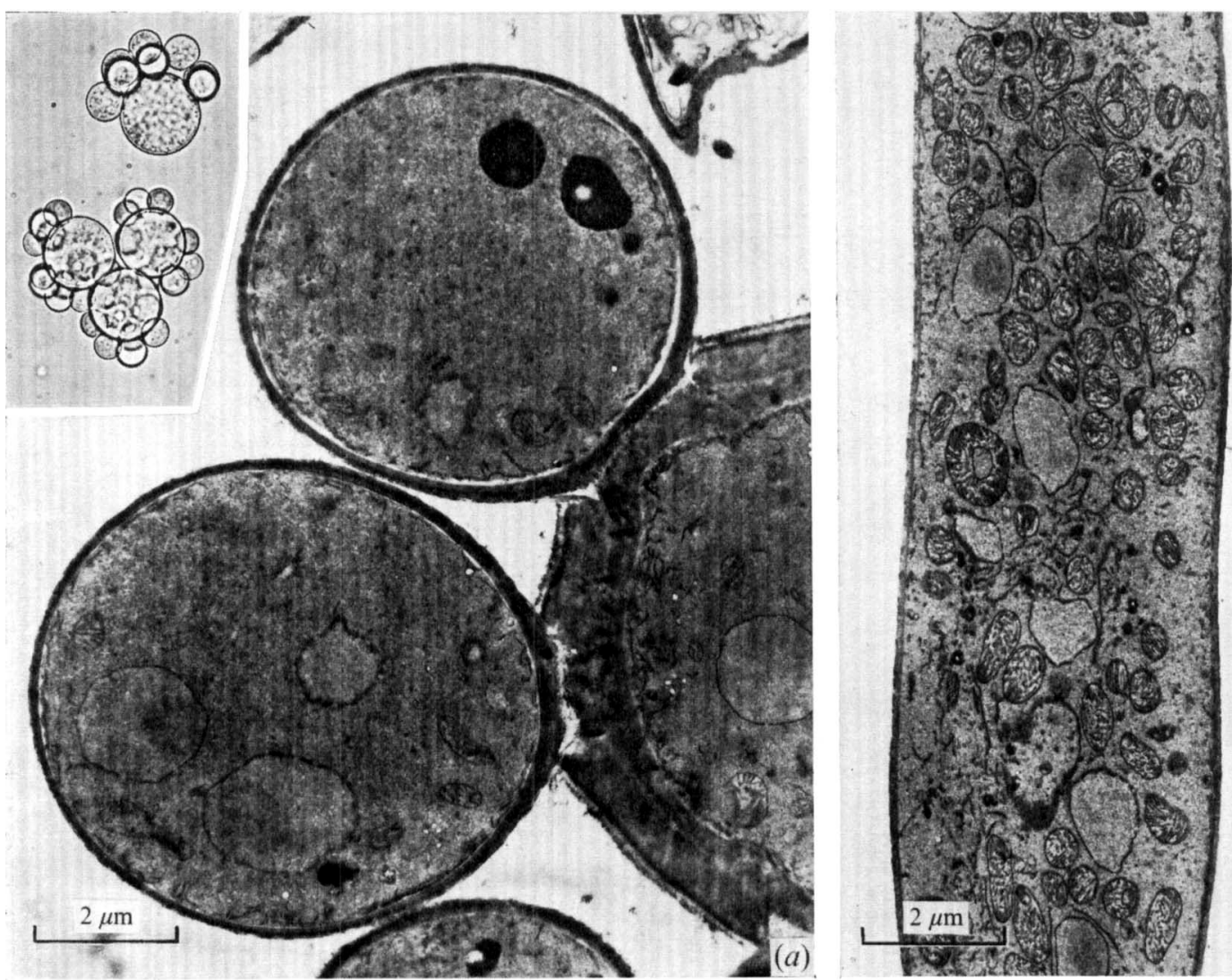

(b)

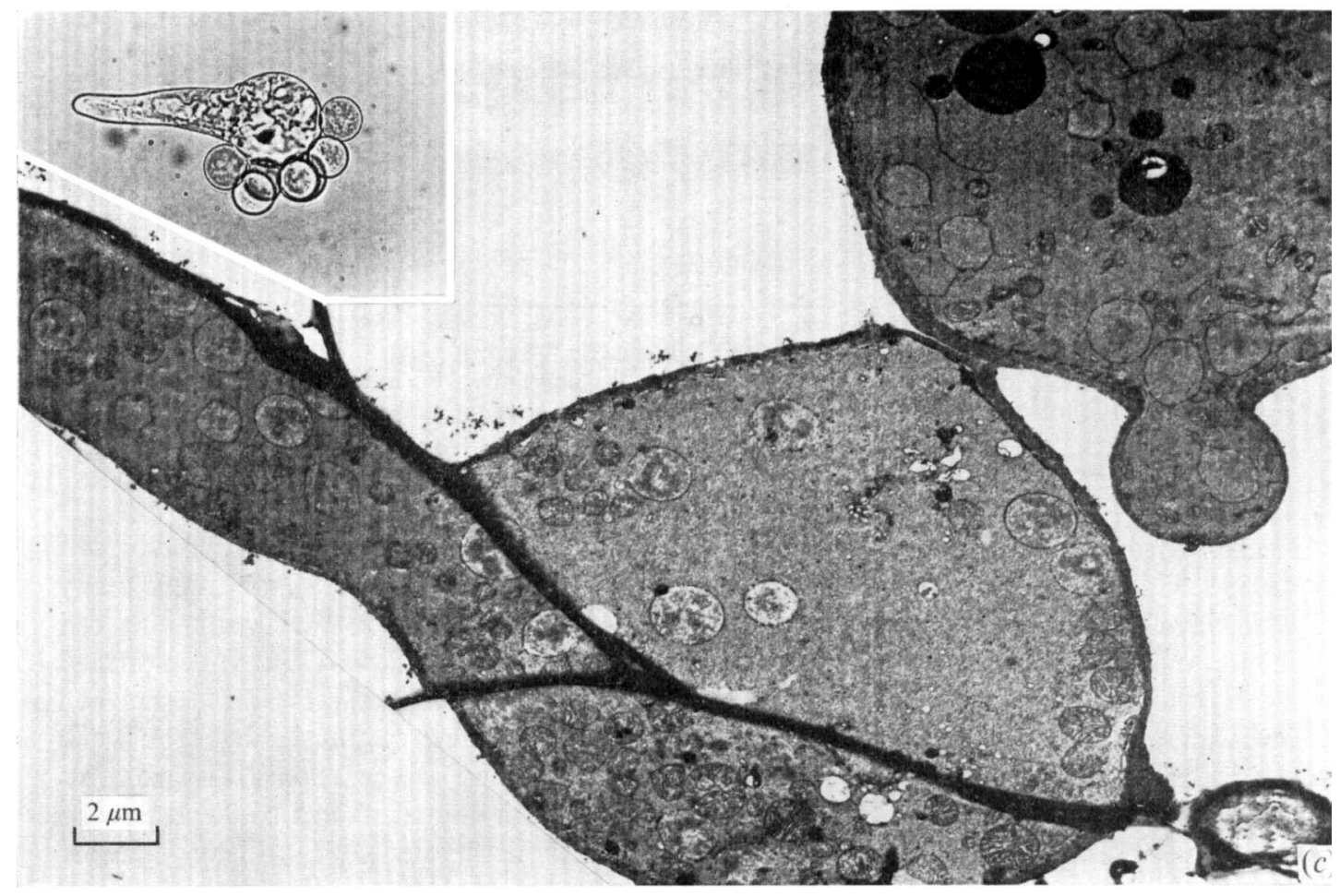

Fig. 5. Electron micrographs. (a) A budding Y-form of $M$. microspora CBSI86.68 grown in liquid GYP medium. (b) M-form of $M$. microspora CBSI 86.68 grown in liquid FYP medium. (c) D-form (dimorphic complex) of $M$. africana also grown in liquid FYP medium. Preparations (a) and (c) were embedded in Epikote; preparation $(b)$ in Araldite. The insets show budding Y-cells and a typical dimorphic cell complex as seen in the light microscope. 


\section{DISCUSSION}

Before discussing dimorphism in Mycotypha, we question the taxonomic position of M. microspora CBSI 86.68. As well as in some minor morphological differences, as for instance in the sporangiole-bearing hyphae, our results have shown it to differ significantly in physiology from $M$. microspora CBS230.32, thus qualifying as a distinct species. In most respects, $M$. microspora CBSI 86.68 assumed a position intermediate between the other $M$. microspora strain and $M$. africana, e.g. the different responses of the two $M$. microspora strains to atmospheric changes, variation of temperature, variation of $\mathrm{pH}$ and addition of protein and respiratory inhibitors, and an intermediate behaviour observed in tests for utilization of carbon sources (unpublished data).

As with Mucor, the influence of many factors on the phenotypic expression of dimorphism in Mycotypha can be interpreted on the basis of a coupling between fermentation and Y-growth and respiration and M-growth. (For the factors tested see the summary in Fig. 4). Chloramphenicol, inhibiting mitochondrial protein synthesis, favoured Y-form development, whereas cycloheximide, an inhibitor of cytoplasmic protein synthesis, did not. Phenylethyl alcohol, by acting on mitochondrial protein synthesis or on cell membranes inhibited, respiration and enhanced Y-form (100\%) in all three strains. Hall \& Kolankaya (1973) found that $0.2 \%$ (v/v) phenylethyl alcohol induced Y-form in $\boldsymbol{M}$. africana only when the glucose concentration was at least $\mathrm{I} \%(\mathrm{w} / \mathrm{v})$. His finding also confirms ours that glucose concentration, increasing at least up to Io $\%(w / v)$, is important for promotion of Y-form.

Blockage of the electron transport chain with antimycin A or KCN promoted Y-form. In contrast, partial inhibition of the respiratory chain, e.g. after addition of rotenone, amytal or thenoyltrifluoracetone, presumably allowed further electron transport over a secondary route, and morphology remained largely unaffected. Inhibition of oxidative phosphorylation with oligomycin, in contrast to uncoupling with 2,4-dinitrophenol, also promoted Y-form. Thus, we may conclude that not only the electron transport itself but also the generation of respiratory energy are prerequisites for the development of mycelial growth and further differentiation into spore-forming structures.

Even on solid substrate, nearly anaerobic conditions induced almost pure Y-growth in all three strains. It is significant that mutants defective in their oxidative metabolism grew as pure Y-form under all conditions tested. It would be advantageous to test additional inhibitors at each of the above sites of action. Nevertheless, we feel that our results do justify our assuming a causal relationship between predominance of fermentation or respiration and $\mathrm{Y}$ - or M-phenotype.

Not all the factors influencing the morphology of Mycotypha to either Y or M growthtype have an obvious effect on the fermentation/respiration equilibrium. We cannot explain how the difference between Y-and M-cell walls can be a direct consequence of changes in the fermentation/respiration equilibrium, or explain the $Y$-form-enhancing effect of increased $\mathrm{PCO}_{2}$, the strong effect of $\mathrm{pH}$ in two of the three strains, and the remarkable influence of temperature on morphologic expression. Carbon dioxide does not simply act by lowering the $\mathrm{pH}$ of the medium, since at $\mathrm{pH}$ values lower than those of our

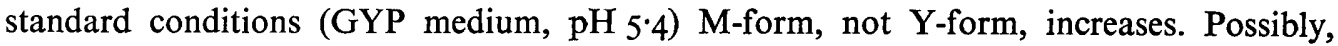
additional fixation of $\mathrm{CO}_{2}$ is responsible for increased $\mathrm{Y}$-growth. Supporting this hypothesis is the observation that biotin, the coenzyme of PEP-carboxylase, enhances Y-growth, even without an additional $\mathrm{CO}_{2}$-supply. The possibility that $\mathrm{CO}_{2}$ is preferentially incorporated into a Y-cell wall protein, as postulated by Bartnicki-García (1963) for Mucor rouxii, 
should also be considered for Mycotypha, especially since $\mathrm{N}$-source enriched medium ( $\mathrm{I} \%$ of various $\mathrm{N}$-sources tested) has a Y-enhancing effect on $M$. africana and $M$. microspora CBSI 86.68 (unpublished data).

It is unlikely that factors which exercise exceedingly complex influences, as do $\mathrm{pH}$ and temperature, merely influence the fermentation/respiration equilibrium. Their primary effects may be to alter membrane structure and permeability, thus influencing transport functions in one or both directions, with multiple consequences for cellular metabolism. The importance of the cell membrane in regulating the $\mathrm{Y} / \mathrm{M}$ alternative is suggested by preliminary results with cyclic adenosine monophosphate. Upon addition of $\mathrm{ro}^{-4} \mathrm{M}$ cyclic AMP under standard conditions, M-form was stimulated. This was even true for $M$. africana - the strain with the most pronounced Y-tendency. Moreover, the same effect could be achieved by culturing at $37^{\circ} \mathrm{C}$ with $10^{-4} \mathrm{M}$-cyclic AMP; in this circumstance not only the Y-enhancing glucose effect, but also the additional temperature effect could at least be partially counteracted by cyclic AMP (unpublished). Further experiments, we believe, will show that regulation of metabolic activities at the cell membrane level plays a decisive role in the phenotypic determination of $\mathrm{Y} / \mathrm{M}$ dimorphism in Mycotypha.

We thank Mrs Margitta Winde for her preparation of electron microscopic sections and photographs, and Mrs Sieglind Mey-Pape for contributing her preliminary experiments with the three Mycotypha strains.

\section{REFERENCES}

BARTNICKI-GARCíA, S. (1963). Symposium on biochemical bases of morphogenesis in fungi. III. Mold-yeast dimorphism of Mucor. Bacteriological Reviews 27, 293-304.

BartNICKI-GarCía, S. (I968). Control of dimorphism in Mucor by hexoses: inhibition of hyphal morphogenesis. Journal of Bacteriology 96, I 586-1594.

BARTNICKI-GARCía, S. \& NicKERSON, W. J. (1962a). Nutrition, growth and morphogenesis of Mucor rouxii. Journal of Bacteriology 84, 84I-858.

BARTNICKI-GARCfA, S. \& NiCKERSON, W. J. (1962 b). Induction of yeastlike development in Mucor by carbon dioxide. Journal of Bacteriology 84, 829-840.

Bleeg, H. S., Leth Bak, A., Christiansen, C., Smith, K. E. \& Stenderup, A. (1972). Mitochondrial DNA and glucose repression in yeast. Biochemical and Biophysical Research Communications 47, 524-530.

Bussel, J., BuCKLeY, P. M., SOMNER, N. F. \& Kosuge, T. (1969). Ultrastructural changes in Rhizopus stolonifer sporangiospores in response to anaerobiosis. Journal of Bacteriology 98, 774-783.

ClARK-WALKER, G. D. (1972). Development of respiration and mitochondria in Mucor genevensis after anaerobic growth: absence of glucose repression. Journal of Bacteriology 109, 399-408.

FOURY, F. \& GOFFEAU, A. (1972). Glucose superrepressed and derepressed respiratory mutants in a 'petitenegative' yeast: Schizosaccharomyces pombe $972 \mathrm{~h}^{-}$. Biochemical and Biophysical Research Communications 48, I53-160.

HAIDLE, C. W. \& STORCK, R. (1966a). Inhibition by cycloheximide of protein and RNA synthesis in Mucor rouxii. Biochemical and Biophysical Research Communications 22, 175-180.

HAIDle, C. W. \& STORCK, R. (1966 b). Control of dimorphism in Mucor rouxii. Journal of Bacteriology 92, 1236-1244.

Hall, M. J. \& Kolankaya, N. (1973). Mould-yeast dimorphism in the genus Mycotypha (Mucorales). Journal of General Microbiology 75, xiv-xv.

Kanetsuna, F. \& CARbonell, L. M. (1971). Cell wall composition of the yeastlike and mycelial forms of Blastomyces dermatitidis. Journal of Bacteriology 106, 946-948.

LEWIN, B. M. (1970). The Molecular Basis of Gene Expression, p. 330. London: Wiley-Interscience.

MCCLARY, D. O. \& BOWERS, W. D. (1967). Structural differentiation of obligately aerobic and facultatively anaerobic yeasts. Journal of Cell Biology 32, 519-524.

NunN, W. D. \& TROPP, B. E. (1972). Effects of phenethyl alcohol on phospholipid metabolism in Escherichia coli. Journal of Bacteriology 109, I62-168. 
OGUR, M., JoHN, R. S. \& NAGAI, S. (I957). Tetrazolium overlay technique for population studies of respiration deficiency in yeast. Science, New York 125, 928-929.

Ramirez-Martinez, J. R. (197I). Paracoccidioides brasiliensis: conversion of yeastlike forms into mycelia in submerged culture. Journal of Bacteriology 105, 523-526.

Romano, A. H. (1966). Dimorphism. The Fungi: An Advanced Treatise. Vol. II. The Fungal Organism, pp. 181-209. Edited by G. C. Ainsworth and A. S. Sussman. New York and London: Academic Press.

SCHeRr, G. H. \& WeAVer, R. H. (1953). The dimorphism phenomenon in yeasts. Bacteriological Reviews I7, 5I-93.

StORCK, R. \& MoRriLl, R. C. (I97I). Respiratory-deficient, yeast-like mutant of Mucor. Biochemical Genetics 5, 467-479.

TerenzI, H. F. \& StorCK, R. (I969). Stimulation of fermentation and yeast-like morphogenesis in Mucor rouxii by phenethyl alcohol. Journal of Bacteriology 97, 1248-126̈. 